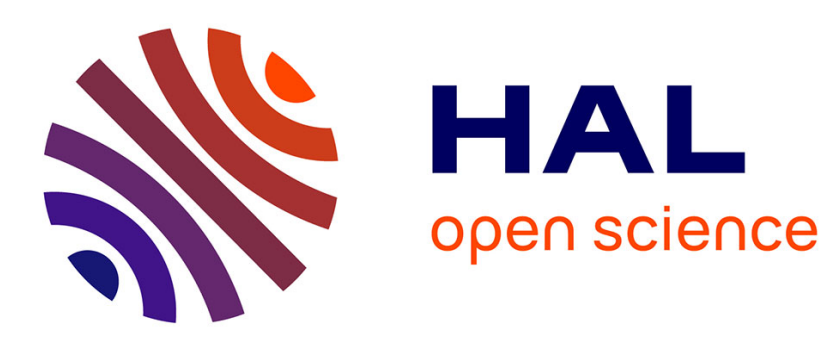

\title{
Inclusive Fitness teleology and Darwinian explanatory pluralism : a theoretical sketch and an application to current controversies
}

\author{
Philippe Huneman
}

\section{To cite this version:}

Philippe Huneman. Inclusive Fitness teleology and Darwinian explanatory pluralism: a theoretical sketch and an application to current controversies. In Biosemiotics: The Natural Foundations of Symbolism, E. Pagni, RS Theisen (ed), Dordrecht, Springer, 2021., In press. hal-03103162

\section{HAL Id: hal-03103162 \\ https://hal.science/hal-03103162}

Submitted on 7 Jan 2021

HAL is a multi-disciplinary open access archive for the deposit and dissemination of scientific research documents, whether they are published or not. The documents may come from teaching and research institutions in France or abroad, or from public or private research centers.
L'archive ouverte pluridisciplinaire HAL, est destinée au dépôt et à la diffusion de documents scientifiques de niveau recherche, publiés ou non, émanant des établissements d'enseignement et de recherche français ou étrangers, des laboratoires publics ou privés. 


\title{
Inclusive Fitness teleology and Darwinian explanatory pluralism : a theo- retical sketch and an application to current controversies.
}

\author{
Philippe Huneman. \\ Institut d'Histoire et de Philosophie des Sciences et des Techniques. (CNRS Université Paris I \\ Panthéon Sorbonne).
}

\begin{abstract}
Formal Darwinism (Grafen 2002, 2007) is a theoretical framework aimed at articulating optimisation models in behavioural ecology and allele dynamics modeling in population genetics. It yields a teleology centered on inclusive fitness maximisation ("IF teleology"), which captures the many aspects of teleology in Darwinian thinking (Huneman 2019b) and supports an explanatory pluralism in evolutionary biology. Based on this framework the present chapter intends to show how the major distinctions regarding kinds of explanation identified in evolutionary biology can be connected and systematized through such explanatory pluralism. Then I will show that it can be redescribed in the terms of Aristotle's four causes, and finally, that it makes sense of the use of two distinct notions of causation. The rest of the paper analyses two examples where this FD-based pluralism and the correlated use of IF teleology allow one to cast a light on current controversies regarding evolutionary theory : the disputed need to overcome the Modern Synthesis of evolution because of non genetic inheritance, biased variation or niche construction; and the opposition of kin selection and multilevel selection regarding the evolution of altruism.
\end{abstract}

Keywords. Explanation; natural selection; inclusive fitness; teleology; causation; pluralism; Aristotle.

\section{Introduction.}

In this chapter I will argue that in the context of the "Formal Darwinism" elaborated by Alan Grafen (Grafen 2002, 2007, 2009, 2015), a framework for thinking of explanatory and causal pluralism in evolutionary biology can be designed. Formal Darwinism (FD) is a view that establishes isomorphisms between this teleology, mathematically understood in terms of 'optimisation programs', and the population genetics, which models allele dynamics in a population at the genetic level (those isomorphisms holds between programs and the Price equation, see Grafen 2002, 2007, 2014, Huneman 2014, 2015). The FD-based pluralism articulates teleology and mechanisms of efficient causes: in Huneman (2019b) I already argued that the teleological kind of explanation can be accounted for in terms of "inclusive fitness", where inclusive fitness (of an organism) measures the benefit of a trait or a strategy as the contribution to the offspring directly produced by the focal organism, plus the contribution to offspring produced by other organisms, 
weighted by the relatedness coefficient ${ }^{1}$. This teleological explanation based on inclusive fitness was there shown to recover the two dimensions of design and contrivance proper to living organisms - namely, organisms seem to be designed, and their parts are contrived toward an apparent purpose. This, as Okasha (2018) demonstrated, makes for a 'unity of purpose' which in ost cases allows the biologist to describe organisms as agents which maximise some magnitude related to survival and reproduction, and named fitness.

In addition, various distinctions of explanatory strategies, and causal concepts, have been proposed in evolutionary biology : Mayr's division of ultimate and proximate causes, functions vs mechanisms, Tinberghen's 'four questions' (Tinberghen 1963), and others. In this chapter, I will use the Formal Darwinism as a tool for pluralism, in order to systematically assess and articulate those divisions. I'll start by sketching the main distinctions between explanatory types in evolutionary biology. Then in a second section, I will trace them back to an explanatory or causal pluralism first stated by Aristotle, who (according to most of the usual translations of his Physics) speaks of the 'four causes', even though one may consider that he meant here 'the four explanantia', aitiai. Given that Aristotle's distinction is highly concerned with what we call the difference between final causes or teleology, and efficient causes or mechanisms, the IF teleology, understood as the genuine Darwinian teleology according to Huneman (2019), will in the third section proves instrumental in making sense of this quadripartition in a Darwinian context. Explanatory pluralism is not an epistemic virtue by itself and that it is not philosophically or scientifically productive unless a formal and conceptual articulation is provided for the different modalities of causation, which is done here.

In the last two sections, I wish to show that this pluralism may be a fruitful framework, by considering two major controversies in evolutionary biology ; the purported need to expand or extend the classical Modern Synthesis framework (Müller 2017), and the controversies over the proper account of the evolution of prosocial traits such as altruism of hymenopteran insects (who don't reproduce but work for the queen) or monkeys emitting alarm calls for the tribe at the cost of their lives.

Those are huge controversies, and this chapter won't solve them, but it will focus on some implicit assumptions therein regarding causal concepts and explanatory perspectives, and argue that the IF teleology, brought in the debates, can contribute making sense of some theoretical divides and overcome disagreements due to the fact that authors talk past each others.

\section{Darwinian teleology and the pluralism of causes.}

\footnotetext{
${ }^{1}$ On inclusive fitness see Birch (2017), which explores all dimensions of the legacy of Hamilton's paper, who coined the main guidelines of the philosophy of social evolution, including this notion of inclusive fitness and the parent notion of kin selection (see below \$4.2.). The coefficient of relatedness is notably difficult to evaluate and even define, but it's mostly thought o be a measure of the statistical association between individuals at a specific locus of their genome.
} 
By providing an isomorphism between the Price equation in population genetics (an equation analytically describing the change of phenotypic value or alele frequencies between two generations in functions of their frequency and fitness) and "optimisation programs" in behavioral ecology (namely, a mathematical description of the hypothetical choice of the best fitness-enhancing strategy by the organism), Formal Darwinism (Grafen 2002; 2007) allows an explanatory pluralism in evolutionary biology. Phenomena can equivalently be understood through optimisation schemes or in terms of allele dynamics, and explanations can - depending upon available information and the nature of the explananda - be run at the gene or at the organism level (Huneman 2014 a, b). This pluralism allows for making sense of a specific kind of teleological explanation, in terms of maximization of inclusive fitness, called IF Teleology (Huneman 2019b). The genuine darwinian teleology is indeed based on this notion of maximizing inclusive fitness. Such account of teleology allows one to make sense both of what I called "intrinsic teleology“" (Huneman 2019b) approaches (such as self-organisation approaches organizational views of functions (e.g. Mossio et al 2009), or the understanding of plasticity as leading evolution by biologists such as West Eberhardt (2003) or philosophers such as Walsh (2015)), and of etiological theory of functions (e.g. Wright 1977; Neander 1991; Griffiths 1994). It makes sense of traits that are apparently not benefitting their bearers, such as the peacock's tail or the worker bee's sterility, and indifferently understands teleological statements regarding organisms or traits (or alleles) (Huneman 2019b). Then, a conceptual analysis of teleology in terms of IF maximisation, embedded within the explanatory pluralism based on Formal Darwinism, provides us with a framework in which one can revisit the various notions of causation that are used by biologists, and I'll do this in this section.

Since Aristotle, the philosophical reflection on causation and explanation has been accompanied by the awareness that causation occurs in many senses. Aristotle famously distinguished four kinds of causes (aitiai ${ }^{2}$ ). Modern science is said to have restricted the 'four causes' to the latter, namely the antecedent efficient cause, mostly understood as a mechanical impetus. Yet, since then, biologists struggled with causal claims that seem to exceed this restriction, especially by allowing for final terms - goals of embryological processes, adaptations that seem to require explanation through design, as Paley famously argued (Huneman 2015, on this argument), functions, which explain $\mathrm{X}$ by invoking some effect of $\mathrm{X}$, therefore exemplifying the logics of final cause. Analytic philosophers put a great weight of attention on functional statements - especially, since the paraphrases by Nagel (1961) or Hempel (1967) in mechanistic terms seemed inconclusive (McLaughlin 29001). Yet Kant's major attempt to account for biological judgement represented indeed a first major treatment of the same problem (Kant 1791; Ginsborg 2001; Huneman 2006).

In this section I will show that FD pluralism, essentially tying IF teleology with dynamics, can be integrated within a general scheme of explanatory pluralism

\footnotetext{
${ }^{2}$ Even though it can also be translated by «'explanation', see above.
} 
in evolutionary biology, and will pinpoint the specific role of teleology. The main idea in the two next sections will be that acknowledging Formal Darwinism and the foundations it provides for Darwinian teleology allows one to build a framework encompassing the main explanatory differences in evolutionary theory.

In the contemporary terms of philosophy of science, explanatory pluralism means that several types of explanation for aspects of a single phenomenon are different but together legitimate. In this chapter, following Aristotle and the usual translation of "aitia", I consider that explanations are searching for causes (Salmon 1994; Woodward 2005), so that explanatory pluralism here goes with causal pluralism. In other contexts I have challenged the exclusivity of causal explanations, understood in sense of causation quite restricted to production - or to a sense that is based on production ${ }^{3}$ - for instance in Huneman (2010, 2018a, 2018b), but here I equate causation in a very general sense with explanation. This chapter will be a contribution to an updating of Aristotle's four causes, which justifies my take here. And given that his quadripartition of causes is very general, I'll start by considering biology in general, even though most of my argument will concern evolutionary biology. If one agrees that, following the usual credo, "Nothing makes sense in biology except under the light of evolution", then the proper Darwinian teleology provides us with the genuine meaning of biological teleology, and I can legitimately proceed from evolutionary biology to biology.

To this extent, I start by reviewing five explanatory/causal pluralisms seen in the literature about biology (\$1), and then I will consider the role of Formal Darwinism and IF teleology in their context (\$2).

A. A major variety of pluralism goes with the difference stated by Ernst Mayr (1961) between "proximate" and "ultimate" causes. Proximate causes occur in the life time of an individual organism whereas ultimate causes pertain to past generations of populations of the organism's species (see Beatty 1994; Ariew 2007). Evolutionary investigations search for ultimate causes, and physiological or molecular genetic investigations search for proximate causes. It has been argued that advances in Evo-Devo and molecular genetics challenge this distinction because for example, if development (embryogenesis, or, more ecologically, niche construction) is relevant to evolution, then the two kinds of causes overlap (Laland et al. 2011; see also Scholl and Pigliucci (2017) for a more nuanced reading of Mayr). However I think that this difference is still to be considered as a reference point; it's indeed still used to organise textbooks, lectures or other presentations.

B. A second difference between kinds of causes holds between a function, and the mechanism that realizes the function. The mechanisms of the cells, glands and vessels in the kidney explain why elimination of toxins occurs; the fact that the function of kidneys is eliminating toxins explain why kidneys are here. Functions and

\footnotetext{
${ }^{3}$ See Glennan (2017) for an account of how production will always be the fundamental meaning of causation
} 
mechanisms are therefore two kinds of causes, so undissociably related that they look like two faces of the same medal.

A caveat here: philosophers argued over the concept of function for decades; some favor the etiological concept of function, according to which " $\mathrm{F}$ is the function of $X$ " means " $F$ has been selected for doing $X$ " (Wright 1977; Neander 1991). This has several shortcomings (e.g. Walsh 2002, Enç 2002), and many refined versions of the etiological view have been proposed, including Griffiths (1994), Kitcher (1994), Garson (2017), Huneman (2013a). The other major family of accounts of functions say that " $F$ is the function of $X$ " means that (a) there is a system $\mathrm{X}$ in which a R-ing activity is carried on, (b) F is part of S and $\mathrm{X}$ is the contribution of $\mathrm{F}$ to $\mathrm{R}$-ing, and (c) X contributes to explain R-ing in a causal way (Cummins 1977, 2002). This second account of functions therefore ascribes to functional concepts another explanatory role than the one I considered here (namely, explaining the presence of $\mathrm{X}$ ), which is the explanatory role considered in etiological views of function. Thus the current division of causes concerns only the function in the sense of etiological theories.

C. A third difference is precisely the one on which Formal Darwinism focuses: optimization vs. dynamics; both would explain why kidney eliminate toxins, but the selective stories at stake are told in different perspectives, dynamics and optimization, which ultimately resort to respectively a physical and an economical languages. It is unclear whether optimisation approaches are causal explanations - it has been argued, by Rice (2012) and Huneman (2018a), that they are indeed not mechanisms, and possibly not causes. In any case this divide concerns a major explanatory dualism in evolutionary biology.

Lastly, dynamics and optimisation seem to be more related to the "ultimate causes" sensu Mayr, because they are about evolution; however proximate causes, for example mammal maternal care behavior can in the same time be understood both in terms of a decision making process oriented towards maximisation of a proxy for fitness, and in terms of dynamics (such as a process of behavioral conditioning).

D. This difference between types of causes also cuts across another important distinction, which sometimes is believed to make sense of the difference between disciplines like population genetics and disciplines like behavioral ecology. The former consider how a trait evolves, namely, either by selection or by drift; therefore they do not consider why the trait is here for. The latter asks about the reasons why those traits or these genes have the fitness they have, they investigate the "causes of selection" (Wade and Kalicz 1990). In fitness terms, this means that some approaches enquire about the causes of fitness (behavioural ecology), and therefore about adaptation; others, like population genetics, investigate the dynamics of evolution and thereby take fitness values as given, notwithstanding their causes. Thus their models can be applied to very different ecological situations, provided that the distribution of fitness values are always similar, as well as the population structure, even though they don't consider the nature of adaptation (namely, what adapta- 
tions are for, ecologically speaking), which will vary according to ecological settings.

E. Finally, biological explanations can be either more focused on traits, or more focused on organisms. This difference pervades all the three other elements of the above distinctions. Such difference when it comes to teleology is refracted into the difference between the "intrinsic teleology" account (which includes the organizational account of function, sensu Mossio et al. 2009), and the selected effects (or etiological) account of functions, because the former is focused on organisms as teleologically oriented, while the second is focused on traits (as targets of selection), as explained in Huneman (2019b)

To sum up, any causal explanations can be either ultimate or proximate (A); and ultimate explanations can either focus on traits, or organisms (E), and they can be couched either in termes of optimality considerations, or in terms of gene dynamics (C). Optimality generally focuses on the reasons for fitness values, while gene dynamics is concerned with the processes though which evolution occurs (D). Finally, something can be in general explained by a function, or the explanation can appeal to a mechanism that explains the function (B). Any genuine explanation can be classified according to each of these distinctions (Figure 1). The next section will detail the relations between these dimensions of distinctions.

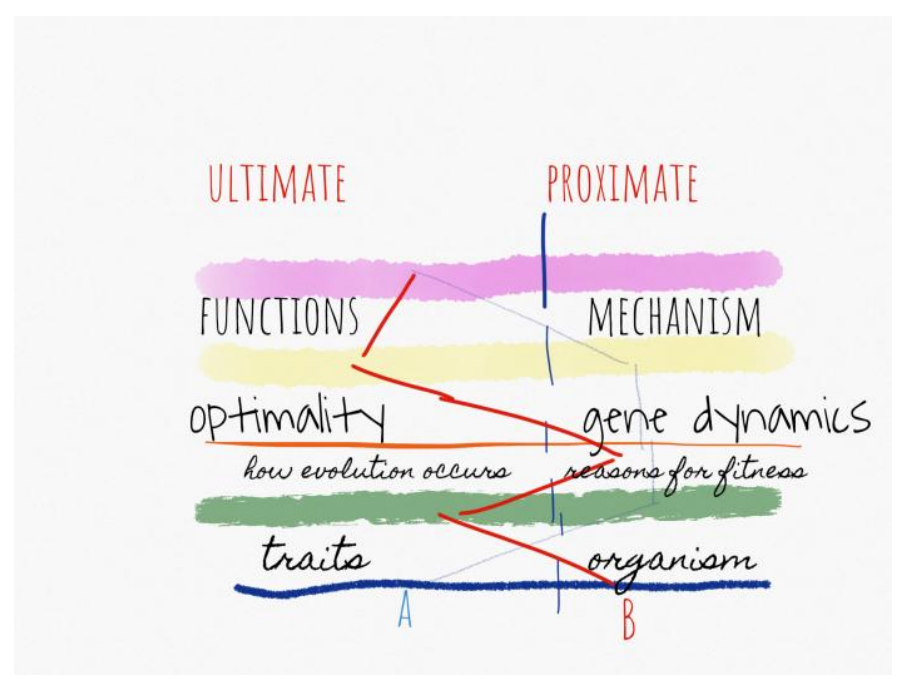

Figure 1.

The five dimensions of explanatory pluralism. (and how two given explanations $A$ and $B$ behave regarding those distinctions).

\section{Formal Darwinism and explanatory pluralism}


In this section I argue that the Formal Darwinism (hereafter FD), a theoretical framework first designed by Grafen $(2002,2007,2014)$ shows how all these distinctions can be interrelated, and finally how an explanatory pluralism proper to evolutionary biology could be articulated.

Regarding distinction $\mathbf{D}$ (bow a trait evolves/why is it for), the first thing is that the dynamics of gene frequencies in evolutionary theory mostly corresponds to the working of selection, while the optimization approach corresponds to the reasons of selection: it wonders why is the fitness (inclusive) higher with this trait?

Yet FD shows how these two questions are related: the workings of selection as a dynamics of allele frequency change exactly underpins the realization of an optimum (under constraints) by an organism seen as a strategy-choser (see Okasha (2018) for a systematic investigation of this model of the strategy-choser). Hence it can account for the perspective difference $\mathbf{D}$ within a unified setting "account for", here, meaning that it shows how the two members of the distinction define legitimate explanations likely to be articulated together in a nonreductive way. .

Now, regarding $\mathbf{E}$ (trait focused-organism focused), FD establishes a link between organism-focused and trait-focused approaches because it explains why the emergence of traits occurs in a designed way, i.e. by contributing to the overall design of the organism (as argued in Huneman 2019b), and yields a genuine teleology - IF teleology - , that embraces both trait-oriented-perspectives and organism-oriented)-perspectives. Hence it accounts for $\mathbf{E}$ within a unified framework, which is the same framework articulating the two sides of $\mathbf{D}$.

As to $\mathbf{B}$ (mechanism-function), teleological explanation pertains to the function of traits; often the function/mechanisms distinction seems to correspond to the distinction $\mathbf{A}$ between ultimate and proximate causes ${ }^{4}$. Yet in general FD shows that, within a same functional attribution, a more fine-grained distinction stands between a certain mechanism or dynamics of allele frequencies and the teleological explanations which uncover the target of the function. In other words, the etiological function $\mathrm{F}$ - when one says " $\mathrm{X}$ has the function $\mathrm{F}^{\text {" }}$ - is carried on by a molecular, cellular and physiological mechanism; but this function itself results from another kind of mechanism, namely the population-level dynamics of gene frequencies across generations, and in turn, such mechanism can also be explained in terms of teleology namely, optimisation of inclusive fitness or IF teleology (Huneman 2019b). Therefore the pair "mechanisms/functions" indicates an explanatory difference more complex than a mere correspondence with the pair "ultimate/proximate" explanation (e.g. of the kidney), since the 'ultimate' part of the explanation - the 'function' in an etiological sense - can be understood at the same time in terms of a population-level mechanism (namely, as an allele frequency change), and as an optimisation.

\footnotetext{
${ }^{4}$ As is clear in the example of the kidney: their function is eliminating toxins; the mechanisms is a complex dynamics of filtering that implies the osmotic properties of cell membranes, and that can be studied at various levels of integration - tissues, cells, metabolic pathways - within the lifetime of the organism.
} 
Such optimisation is the maximisation of inclusive fitness, which has been shown to be the most systematic sense of teleology in a Darwinian context $\mathrm{Hu}$ neman 2019b). Thus, finally, when it comes to the difference $\mathbf{A}$ between ultimate and proximate in general, dynamics and optimization as understood by FD both pertain to ultimate causation. Thereby the distinction $\mathbf{C}$ further divides each member of distinction $\mathbf{A}$ into two sub-categories: dynamical and optimal. The category "Ultimate cause" therefore has to be divided into a dynamics of alleles, which is so to say a "proximate ultimate" cause, and IF teleology, which is an "ultimate ultimate" cause, and both are connected through the isomorphisms stated by Formal Darwinism.

Thus, there are two lessons from this examination of the relation between differences in explanatory types : the five explanatory pluralisms $\mathbf{A}-\mathbf{E}$ that pervade evolutionary biology, and even biology in general (whence one considers distinction A), can be articulated through FD; and the same reasoning shows that there are grades of teleologically ultimate explanations, and that IF provides the "ultimate ultimate" cause in biology.

\section{The four causes, revisited.}

Aristotle famously divided causes into four kinds: efficient (material events which produce the consequent); formal (the essence of the event, i.e. the usual answer to the question "what is it?"); final (the goal of the event) ; material (the substance of the event) ${ }^{5}$. Those categories of course have been mainly given up with the scientific revolution and the change in the ideas of explanations, causation and law brought about by modern physics; however, the Aristotelian inspiration may sometimes help to draw the conceptual space of a scientific field. Especially, Tinberghen explicitly thought about it by distinguishing four causes, even though they do not correspond one-to-one to Aristotle's causes (Tinberghen 19636). According to him, a biological behavior calls for explanations in termes of its development, its mechanisms, its evolutionary history, and finally its adaptive meaning, or function. Here, "function" would correspond to final cause, "development" to efficient cause, "mechanism" to material cause ("formal cause" is harder to get into the picture).

\footnotetext{
${ }^{5}$ Here is the text where Aristotle first set this distinction. "In one way, then, that out of which a thing comes to be and which persists, is called a cause, e.g. the bronze of the statue, the silver of the bowl, and the genera of which the bronze and the silver are species.

In another way, the form or the archetype, i.e. the definition of the essence, and its genera, are called causes (e.g. of the octave the relation of 2:1, and generally number), and the parts in the definition.

Again, the primary source of the change or rest; e.g. the man who deliberated is a cause, the father is cause of the child, and generally what makes of what is made and what changes of what is changed.

Again, in the sense of end or that for the sake of which a thing is done, e.g. health is the cause of walking about. ('Why is he walking about?' We say: 'To be healthy', and, having said that, we think we have assigned the cause.) " (Physics, 194b24-195a3, tr. Barnes.)

6 See also Hladky and Halvicek (2013) on the relation between this quadripartition and Aristotle's four causes.
} 
Now, in the case of Formal Darwinism, the dynamics of gene frequencies would correspond to the "efficient cause", since it is the temporal process that brings about the trait along evolutionary time. The "formal cause" would be the function of the trait, namely what it does that explains why it is here. And the "final cause" would be the maximization of inclusive fitness, which is even more general than the function itself. In this case, according to our typology, population genetics would consider both the material and the efficient causes (respectively the alleles and their dynamics); the behavioral ecology considers the formal cause, namely the function, and the final cause - namely, to leave as many offspring as possible through direct and indirect ways, i.e., maximizing inclusive fitness.

Thus within evolutionary biology FD allows us to recover a quadruple partition of causes that updates an aristotelian-style metaphysical division. And, as in Aristotle's physics, all those explanations are compatible: taken together they constitute a complete explanation of the phenomenon under focus.

However, the pluralism we just considered until now was about types of causes, like Aristotle's partition, which could map onto types of explanations. Yet there is another, philosophical, pluralism, which concerns the concept of causation (or the nature of causation itself, if one wants) (e.g. Godfrey-Smith 2010). Here, the main distinction is about two very large families of theories of causation, which corresponds to two intuitions: "A causes B" can mean (1) that "if A had not occurred, B would not have occurred", or it can mean (2) "there is a physical process through which B stems from A". The first families can be called "differencemaking causation" (Menzies, 2002), and comprehend the so called counterfactual theories of causation, first elaborated by Lewis (1975) (e.g. Hall and Paul, 2003), the "manipulationnist" theories of causation - namely, an intervention on variable A changes, mutatis mutandis, variable B -, or the probabilistic theories of causation i.e., the difference $\mathrm{A}$ makes on $\mathrm{B}$ is probability raising. The second family of accounts is the "process causation", first elaborated by Salmon's theory of transmitted mark (Salmon 1984), then refined (Dowe, 2000). Hall (2002) argued that the two families, corresponding to the two very general concepts of causation, are heterogeneous - especially, features of the latter such as locality aren't possessed by the former and reciprocally. Glennan (2017) argued that Salmon's focus on fundamental physics is unnecessary, and that the process account may hold even though not all causal processes stand at the level of particle physics. In any case, if Hall is right regarding concept dualism, this entails a general pluralism in scientific explanations, when causal statements can sometimes be uttered according to one concept but not to the other ${ }^{7}$.

This difference directly impinges upon evolutionary biology. Actually, the Formal Darwinism states an equivalence between these two kinds of causation: dynamics of gene frequencies concerns causation in the sense of a process, while optimization clearly concerns causation in the sense of difference-making, since the traits

\footnotetext{
${ }^{7}$ In Huneman $(2012,2013 b)$ I argued that natural selection can be understood as a causal explanation when causation is taken in the sense of difference-making, and I defended an account of this causation in terms of counterfactuals - but not in the sense of production processes.
} 
that make the highest difference upon inclusive fitness will evolve. Therefore, the explanatory pluralism stated above in $\$ 1$, which systematizes the distinctions $\mathbf{A}-\mathbf{E}$, is supplemented along another dimension by a causal pluralism in the form of an equivalence between difference-making and process causation in evolutionary biology, to the extent that do hold equivalences between behavioral ecology and population genetics (instantiating those two distinct concepts of causation) established by FD.

Until then, I proposed that the pluralism proper to FD, and especially the kind of teleology defined on this basis (IF Maximisation) makes room for a reassessment of Aristotle's causal pluralism. The major distinctions regarding explanations in biology (labelled A-E) were translated into a unity of teleology and mechanisms that is based on the ultimate teleology provided by FD, namely IF teleology. IF also allows one to make sense of the uses of two concepts of causation, the difference-making concept, and the process concept, and provides possible connections between those two causal schemes.

To sum up this examination of the relation between Aristotle's classical theory of causes, and the current practical distinctions one can make between various explanatory types in evolutionary biology, I'll say that various kinds of explanations, distinguished by considering the pluralism involved by FD, could be re-thought along the lines of Aristotle's division of causes. The last section of this paper will now apply this view in order to show that it could contribute to solve current controversies in the field, because many debates are either triggered by a confusion between kinds of causes, or by a disagreement about which one should be in priority handled, for methodological or pragmatic reasons.

\section{Pluralism and the current controversies}

\subsection{Pluralism and the current controversies : a- the so-called 'extended synthesis'.}

There is an ongoing controversy about whether one should extend or expand evolutionary theory (Pigliucci and Muller 2011, Pigliucci 2007, Jablonka and Lamb 2005, Laland et al 2014; Müller 2017, etc.) in the light of findings by EvoDevo or behavioral ecology or ecology; or not (e.g. Lynch, 2005; Wray et al 2014) ${ }^{8}$. The alternative theories are very varied; however they all insist, in different ways and with distinct emphases, on the fact that the Modern Synthesis cannot integrate new findings of developmental and molecular biology and genomics, about the non-genetic forms of inheritance such as parental effects (Bonduriansky and Day 2009) or epigenetics (Jablonka and Raz 2009; Danchin et al 2011); the role of organisms in shaping their environment (niche construction, Odling-Smee et al. 2003); the complexities of genomic systems (Griffiths and Stotz 2013); or the

\footnotetext{
${ }^{8}$ Various approaches to the alternative theories are collected in Huneman and Walsh (2017). I tried to show which empirical data would be required to trigger a real revolution of the explanatory scheme proper to the Modern Synthesis, rather than a piecemeal rearrangement (Huneman 2017). The perspective chosen in this chapter does not contradict this more extended argument.
} 
prevalence of phenotypic plasticity (West Eberhardt 2003) and developmental biases (Brakefield 2008, Uller et al. 2019). Many of these claims challenge the genocentric view of the Modern Synthesis, which conferred to population genetics the key role of modeling the process of evolution by natural selection ${ }^{9}$ - and in the contrary, they call for a "return of the organism" (Bateson 2005). I argued already that FD pluralism may conciliate the organism-centered and the gene-centered views, because it holds together gene dynamics and organismal teleology (see $\mathrm{Hu}-$ neman 2014b). Here, I consider another avenue of conciliating claims, regarding the pluralism of explanation and causation, which is the focus of this chapter.

As summed up by Huxley to Mayr in 1951, the position that the alternative to MS intend to challenge is the following: "Natural selection, acting on the heritable variation provided by the mutations and recombination of a Mendelian genetic constitution, is the main agency of biological evolution" ${ }^{10}$. Among many biologically disputed issues, one philosophical argument coined by the challengers of Modern Synthesis is about causes of adaptation : the claim is that cumulative selection on small variation is not the actual cause of adaptation. Based on the interpretation of natural selection called "the statisticalist interpretation" (Walsh et al 2018), which is out of the scope of this chapter, Denis Walsh developed a very sophisticated argument according to which natural selection causes the spreading of adaptive traits but does not cause their emergence (see also Walsh 1998). The latter is rather due to developmental process in some individuals, especially adaptive plasticity (Wash 2010) or possibly self-organisation (Walsh 2003). In the introduction of their extended synthesis book, Pigliucci and Müller (2011) try to give a general account of the rationale for extending the evolutionary synthesis. The general idea is that Darwin and the Modern Synthesis thinkers had a statistical view of evolution by natural selection, mainly counting representations of genes generation after generation, because they did not know the mechanisms of variation and production of new traits. But now that we can access these mechanisms, the overall picture of evolution and adaptation changes: hence we switch from a "statistical" conception of causation in evolution to a mechanical "conception" of causation". As they say, "the shift of emphasis from statistical correlation to mechanistic causation arguably represents the most critical change in evolutionary theory today." Interestingly, these two views are grounded on the distinction stated above between the concepts of causation : according to Pigliucci (2007), the 'extended synthesis' would move us towards a process-view of causation and explanation, instead of the difference-making view, implicit in any probabilistic account. Thus, for the same reason, the FD pluralism sketched here allows one to conciliate them and solve the dispute, as I'll indicate it now.

\footnotetext{
${ }^{9}$ For example: "The core of the synthetic theory is pretty much just the theory of population genetics" (Beatty 1986, p. 125).

${ }^{10}$ Julian Huxley to Ernst Mayr, 3 September 1951. Papers of Ernst Mayr. HUGFP 14.15 Box 1. Harvard University Archives, Cambridge, MA.

${ }^{11}$ I gave a direct extended critique of this argument in Huneman (2019a), based on analysis of some explanatory practices in postgenomic evolutionary biology, but here I focus on the metaphysics of causation.
} 
Even if they are quite different, both reformist claims mentioned here are saying that evolution by natural selection according to MS is a statistical explanation, but that the underlying mechanisms are the genuine causes of adaptation (for Walsh) or evolution (for Pigliucci and Müller). However this overlooks the complex picture of evolution by natural selection provided by FD. Granted, there is a dynamics of gene frequencies, which corresponds to a statistical explanation, and which especially brackets the mechanisms of variation. Yet the inference that new science of mechanisms would give a better or truer account of adaptation or evolution is not justified, since we just saw that this statistical explanation is equivalent to another one couched in non-statistical terms: the teleological one, or optimization. Therefore, the need to extend the MS can not be attributed to the fact that MS was only a dynamics of genes, statistically modeled, because this is only one side of the FD equivalence. And, on the other side, IF teleology is what explains adaptations as such, as it unravels the final cause that account for why a given trait is there - namely its maximizing inclusive fitness.

To be more precise, the emphasis put by Walsh (2010, 2013), as by many biologists and philosophers who support a radical reform of the Modern Synthesis, on mechanisms of variation versus natural selection, envelops the assumption that natural selection only explains the spreading of the traits, but not their origin. There is a longstanding debate on this issue -(Neander 1995 ; Walsh 1998), opposing what Neander has coined the 'Negative view' (i.e., the abovementioned assumption about what selection explains) and a 'Creative view' of selection. I won't survey it here; let's just notice that the Darwinians of the Modern Synthesis were concerned by this issue, and that, as Beatty $(2016,2019)$ has argued, one of the hallmarks of their view is the commitment to the idea of a "creativity of natural selection". This means that for them, and against, first, the Mendelians and then, some the opponents of Mayr or Dobzhansky, such as Goldschmidt, natural selection was not only a sieve that prevents the less fit to spread and therefore let the fittest spread, but it also shapes the adapted traits, because across generations it constructs the gene pool from which new variants are built.

The FD pluralism advocated here includes a teleological explanation accounts for this 'creativity' view. Why? The whole population genetics modeling of the action of selection can be seen as a statistical explanation of what happens, and therefore, is mostly concerned by the spreading of the adapted traits, since those traits are originally brought about by mutation and recombination in some genotypes. However if we switch to the a teleological view - and this perspective is always available, because of the nature of IF teleology, as rooted in the equivalences between allele dynamics and optimization (Grafen 2002, 2007) -, then, the adapted traits themselves (and not their spreading) are here because they maximise inclusive fitness. The teleological argument indeed is formulated as : "since trait $\mathrm{X}$ maximises inclusive fitness, it will be the strategy adapted by organisms of the kind considered, in the environment and population under focus"; and under this view, no population-level process statistically described is among the explanantia. Hence, against the 'negative' view, which is presupposed by the arguments of those who think Modern Synthesis should be overcome by a mechanistic and 
non-statistical understanding of adaptation, natural selection really explains the fact than the adaptive traits are there ${ }^{12}$.

To sum up here, the IF teleology allows one to downplay one of the epistemological arguments put forth by defenders of an alternative to the Modern Synthesis - namely, the opposition between a supposedly statistical knowledge in MS, and a mechanistic knowledge brought for by its alternatives - , because not all aspects of the overall explanatory picture of MS have been considered by such critical account.

\subsection{Pluralism and the current controversies: b-Explaining altruism: the multilevel / kin selec- tion controversy, sketching an answer.}

A huge debate has been going on for three decades in evolutionary biology, about what is the cause or at least best explains some prosocial traits, i.e. the traits that are costly for their bearer and beneficial for others (often called altruistic, see West et al. 2017). The obvious evolutionary problem here is that these altruist traits should be counter-selected, but in fact they are everywhere: sterile workers in hymenopterans insects, alarm calls in antelope or monkeys, helping behaviors in many species etc. The emergence and maintenance of these traits raises therefore a deep problem for classical Darwinism.

Two main theories have been advanced to understand this: the first one (suggested by Hamilton, 1963) is the kin selection/inclusive fitness theory, according to which a trait evolves if its benefit is higher than the cost mitigated by the "relatedness". A proxy for relatedness is kinship; however relatedness is in general more complicated than this (Frank, 2006). This account of altruism is summarized by the famous "Hamilton's rule", $b>r c$ - where $b$ is the benefit for the receiver, $c$ the cost for the focal actor and $r$ their relatedness. The rule can compares the two components of inclusive fitness, namely the direct $(-c)$ and indirect $(b r)$ fitness benefits.

The other view is called Multi-Level Selection (MLS) theory (Sober and Wilson, 1998, Okasha 2006, Damuth and Heisler 1988). It is grounded in the following idea: if you suppose that evolution takes place in a population divided into groups, altruists compared to selfish individuals or behavioral strategies score less; however groups including many altruists fare better than groups with a lower proportion of altruist, since altruists per definition invest resources, energy and time in the group's welfare. Therefore evolution can be considered as resulting from the addition of intragroup competition (which favors selfish elements) and intergroup competition (which favors altruists): when the second term is higher, altruism can evolve.

\footnotetext{
12 To be successful the argument should in fact consider cumulative selection, which is what underlies complex adaptation, as the trait maximizing inclusive fitness. But this isn't central here. The importance of cumulative selection to justify teleology is highlighted in Huneman (2019b)
} 
Some authors have claimed that one of these views is just a particular case of the other : Sober and Wilson (1998) held that multilevel selection is the most general theory and includes kin selection as a case where groups are kin groups; Nowak (2006) claimed that kin selection is only one among other explanations of cooperation and that it is overstated (Nowak et. al 2009). West et al. (2007), Lehmann and Keller (2006), Lehmann West and Roze (2007), etc. argued that the evolutionary mechanism is always kin selection, and Abbott et al. (2011), West and Gardner (2011), Ferriere and Michod (2011) argued that the kin selection/inclusive fitness theory is the most powerful and accurate one ${ }^{13}$.

The main argument of the tenants of MLS is that it captures the real causal structure of evolution, while kin selection may correctly represent what happens to genes, but does not capture anything except a shadow of the causal processes (Sober and Wilson 1998). Interestingly they invoke the same distinction between causal and pseudo-causal distinction (mentioned above \$4.1) as Walsh (2003) did regarding adaptations. In effect, they say that what causes evolution of altruism is, in real life, competition between groups, while, by overlooking real interactions between organisms, the kin selection view cannot see this. This justifies their "averaging fallacy" argument, which in essence means that computing the fitness of organisms by averaging their reproductive success in different contexts (i.e., groups) may give a correct estimation of final gene frequencies, but neglects the causes of this final frequency, i.e. their belonging to specific groups, since by definition the averaging neglects this fact. This argument connects to Sober and Lewontin (1982) critique of genic selectionism, where allelic selectionist is said to be blind to the level of real causes, which stand at the level of the genotypes; the classic example here is the case of the superiority of heterozygotes, as happens with recessive alleles for malaria resistance in sickle cell anemia ${ }^{14}$.

On the contrary, supporters of inclusive fitness would say that the causes of evolution are occurring at the level of alleles increasing or decreasing in frequency in accordance to their contribution to the fitness of the relatives, so that in all cases presented by supporters of MLS (e.g. Traulsen and Nowak 2006), what really happens is a process of kin selection (Lehmann et al. 2007). They add that multilevel selection is most of the time mathematically intractable (West et al. 2007b), which provides a substantial methodological advantage to kin selection models.

But clearly, the two camps don't focus on the same causal aspects: the MLS supporters argue that the causal story is the competition between groups, so their causally relevant facts are intergroup competition and intragroup competition; the kin selection theorists argue than the causally relevant facts are direct fitness benefits and indirect fitness benefits. Therefore, in the first approach what is crucial to determine is the partition of the population into groups; and in the

\footnotetext{
13 But see Birch (2017) for a comprehensive account of what Nowak et al. (2009) really meant about kin selection, and how the controversy mostly focuses on something else.

${ }^{14}$ Because being heterozygote is a property of the genotype, not the allele; hence the relevant causal property stands at the genotypic, not the allelic, level.
} 
second one what is crucial is relatedness, because it allows one to define and measure indirect benefits. And it seems that relatedness is tractable in an easier way than group partitioning, which could explain the fact that most accounts of social evolution are couched in terms of kin selection (West et al. 2010).

However, there are equivalences between these stories (for an in-depth analysis of those equivalences see Birch 2017). As Kerr and Godfrey Smith (2002) have shown, a multilevel approach of evolution, in general, is mathematically equivalent to an approach where fitness of individuals is contextualized over groups and then computed across generations. More simply, the more the intergroup competition increases relative to intragroup competition, the more MLS you have for the pro-social (altruists) traits: but this means that the between-group variance relatively overcomes the intragroup variance. This in turn entails that relatedness increases in each set of individuals interacting with a focal individual and then in general, which in the end means that kin selection increases; and reciprocally (Franck, 1995; Foster et al. 2006; West et al. 2007). Let's call (E) this equivalence.

Both camps therefore claim that they provide a causal story of the evolution of social traits, but disagree on what is the main causal fact - group partition vs. relatedness. Central to such dispute is the status of causal explanations in biology, even if it's often not made explicit. MLS theory is said to capture the causal story because here causation is thought in terms of mechanisms: the process by which some groups are superseding other groups, then changing the frequencies of social individuals. According to Darwinian cultural evolutionists like Boyd and Richerson this is well exemplified by two ethnies previously living in Africa, the Nuer and the Dinka, in Sudan: Nuers didn't have the same policy for redistributing cattle, since they were more involved in providing cattle for the whole tribe, beyond what one would need for oneself; as a result, between 1820 and 1890 they took over most of the Dinka's territory, and increased by four times their territory (Kelly 1985).

The kin selection view is, in turn, articulated in terms of variables making differences to outcomes: if one increases or decreases the relatedness, then, whatever the ecological processes occurring in the population - competition, predation etc.-, the expected outcome (i.e. relative frequencies of social individuals) increases or decreases.

So besides all methodological and biological differences between kin selection approaches and MLS approaches of altruism, stands between them a difference between two conceptions of causation: a process view on the one hand, a difference-making view on the other (according to the distinction made in \$3). Thus, it seems that the dispute about which is the real causal story and therefore the best account is doomed to go on forever since the two sides talk past each other. However, given that I previously articulated a pluralistic view of causal explanations in evolutionary biology $(\$ 3)$, there might be a way to make sense of that controversy. 
So how to conciliate kin selection models and MLS models, from the viewpoint of the pluralism of explanation concepts? First, recall that kin selection theory can be easily formulated in terms of inclusive fitness theory (Hamilton 1963, Birch 2017): the former is a story about dynamics of gene frequencies, since the fitness of alleles is computed in the model ; the latter is the same story understood in terms of optimization of the organism's strategy: altruists evolve if and only if they maximize inclusive fitness, which is, remember, the addition of what the focal strategy brings to other organisms (mitigated by relatedness), and the cost the organism incurs (both expressed in fitness units). The former formulation, namely kin selection, stands at the level of alleles, while the latter, inclusive fitness, considers organisms, since it computes inclusive fitness at their level.

But, as I said, the inclusive fitness account also pertains to a differencemaking view of causation. And the FD equivalences entail, as we have seen ( $(3)$, that such causal approach can be articulated to causal explanations of another nature, namely process causation, which is at stake in models of alleles dynamics. Now, this equivalence will allow making sense of the controversy about kin selection and MLS. How?

In effect, given the above mentioned equivalence (E) between varying relatedness in kin selection perspective and modifying the intergroup/intragroup competition ratio in the MLS view, the latter appears to be, at the level of organisms, the causal explanation in terms of causation-as-processes that exactly corresponds to the difference-making view of inclusive fitness. Ultimately, our framework therefore provides a pluralist explanation of evolution of social traits at three levels (Table 1). Let's unpack it now. MLS is a causal (sensu processes) explanation at the level of organisms; through (E) it is equivalent to a causal (sensu processes) explanation at the level of alleles, namely kin selection models; and the latter, through the FD equivalence, corresponds to a causal explanation (sensu differencemaking), stated at the level of organisms, namely the inclusive fitness approach. The two equivalencies (FD and E) about models finally suport a pluralism of causal concepts and levels of explanation. And the teleological explanation, namely the IF teleology, is the more encompassing one since it can account for different kinds of processes at both levels (organisms, alleles) - in other words, it is the most general account of the evolution of social traits- that is, the most generic one, since it can be predicated on the basis of a variety of different genetic makeups that satisfy distinct models of kin selection.

\section{Table 1.}

Concept of Level Type of ex-
causation




\begin{tabular}{llll}
$\begin{array}{l}\text { Inclusive } \\
\text { fitness }\end{array}$ & $\begin{array}{l}\text { Difference } \\
\text { Making }\end{array}$ & Organisms & Teleological \\
$\begin{array}{l}\text { Kin Selec- } \\
\text { tion }\end{array}$ & Process & Genes & Mechanical \\
MLS & Process & Organisms & Mechanical \\
\hline
\end{tabular}

Therefore the pluralism about evolution of social behavior that is based, in the present approach, upon the FD pluralism, will allow for various grades of genericity. IF teleology approach is the most generic, and then, details about genetic makeups of altruism and selfishness will allow for more realistic models, which in turn model more possible structures of the allele dynamics, namely the various kin selection models of different gene pools.

Of course, this is not supposed to close the controversies about social evolution. I just suggested that considering the general framework for explanatory pluralism provided by FD to evolutionary biology, and especially acknowledging the legitimacy of Darwinian teleology understood as IF teleology, which constitutes the 'ultimate ultimate causation', may help to identify the issues where discussants talk past each other and the issues where they are in agreement (or, not disagreeing) with each other even while not acknowledge it. While in those debates equivalence (E) has been often appealed to in order to support a pluralism between explanations of social evolution, putting FD into the picture allows one to provide a more complete table of explanatory types, understand bridges between distinct explanations that use various causation concepts and stand at distinct levels and finally, allows for grades of generality that differently realize a same IF teleology explanation.

\section{Conclusions}

In this paper I considered the uses of a view of evolutionary theory based on Formal Darwinism, which confers an overarching role to a specific teleological explanation understood in terms of the maximization of inclusive fitness. On this basis, I presented a general scheme for making sense of explanatory pluralism in evolutionary biology, integrating five classical views of explanatory differences, and then, both the four types of causes and the two notions of causation, and sketched the position occupied by the Darwinian IF teleology into this scheme.

This is not only a general investigation of the scientific image of biology aimed at philosophers; more importantly, it is intended to provide a framework in 
which some controversies can be solved, and some very current challenges to classical evolutionary can be addressed and assessed. This is why I indicated how an awareness of such explanatory and causal pluralism, updating (for the former) the Aristotelian quadripartition, may help biologists in dealing with two massive controversies in evolutionary theory, namely the call for an alternative explanatory scheme integrating non genetic inheritance, facilitated variation or niche construction, and the debates about the proper model and theory for accounting for the evolution of prosocial traits. Because Aristotle's distinctions have been fruitful to understand science across the ages, I think that an attempt to update these distinctions by considering various explanatory practices in evolutionary biology could be useful.

\section{References.}

Ariew, A. R., Cummins, R. and Perlman, M. (eds) (2002) Functions, Oxford: Oxford University Press.

Bateson P. (2005), "The Return of the Whole Organism", Journal of Biosciences 30(1): 31-39.

Beatty, J. (1986) "The Synthesis and the Synthetic Theory". In Integrating Scientific

Disciplines, ed. W. Bechtel, 125-136. The Hague: Nijhoff.

Beatty, J. (1988) "Ecology and Evolutionary Biology in the War and Postwar

Years: Questions and Comments." Journal of the History of Biology 21: 245-263.

Beatty, J. (1994) "The Proximate/Ultimate Distinction in the Multiple Careers of Ernst Mayr". Biology and Philosophy 9: 333-356.

Beatty, J. (2016) "The Creativity of Natural Selection? Part I: Darwin, Darwinism, and the Mutationists". Journal of the History of Biology 49: 659.

Beatty J. (2019) "The Creativity of Natural Selection? Part II: The Synthesis and Since". Journal of the History of Biology https://doi.org/10.1007/s10739-019-09583-4

Birch J. (2017) "The inclusive fitness controversy: finding a way forward". R. Soc. open sci. 4: 170335.

Birch J. (2017) Philosophy of social evolution. New-York: Oxford University Press.

Bonduriansky, R, Day T (2009) "Nongenetic Inheritance and Its Evolutionary

Implications." Annual Review of Ecology, Evolution, and Systematics 40: 103-125.

Brakefield, P. M. (2006) "Evo-Devo and Constraints On Selection". Trends in

Ecology \& Evolution 21: 362-368.

Buller, D. J. (ed.) (1999) Function, Selection, and Design, Albany, NY: SUNY Press.

Burt A, Trivers R. (2006) Genes in Conflict: The Biology of Selfish Genetic Elements. Cambridge, MA: Belknap Press of Harvard University Press.

Cummins, R. (1977) "Functional Analysis',"Journal of Philosophy, 72:741-65.

Cummins, R. (2002) "Neo-Teleology", in Ariew et al. [2002], pp. 157-72.

Damuth J, Heisler IL. (1988) "Alternative formulations of multilevel selection". Biology and Philosophy. 3:407-430.

Danchin, E, Pocheville A. (2014) "Inheritance Is Where Physiology Meets Evolution.” Journal of Physiology 592 (11): 2307-2317. 
Danchin, E, Charmantier A, Champagne FA, Mesoudi A, Pujol P, Blanchet S. (2011) "Beyond DNA: Integrating Inclusive Inheritance into an Extended Theory of Evolution." Nature Reviews Genetics 12: 475-486.

Darwin, C. (1862) On the various contrivances by which British and foreign orchids are fertilised by insects, and on the good effects of intercrossing. London: John Murray.

Dowe P (2000) Physical Causation, Cambridge: Cambridge University Press.

Enç B. (2002) "Indeterminacy of Function Attributions" in Ariew A, Cummins R, Perlman M (eds.), Functions: New Essays in the Philosophy of Psychology and Biology.

New-York: Oxford University Press. pp. 291

Ferrière R., Michod R. (2011) "Inclusive fitness in evolution". Nature. 24;471(7339): E6-8

Fisher R. (1930) The genetical theory of natural selection. London

Fisher R. (1932) "The bearing of genetics on theories of evolution." Science progress , 27: 273-287.

Frank SA. "Social selection". In: Fox CW, Wolf JB, eds. Evolutionary Genetics: Concepts and Case Studies. Oxford: Oxford University Press; 2006:350-336.

Frank, S. A., Slatkin, M. (1992) 'Fisher's Fundamental Theorem of Natural Selection", Trends in Ecology and Evolution, 7, pp. 92-5.

Gardner A (2008) "The Price equation". Curr Biol 18(5):R198-R202

Gardner A (2009) “Adaptation as organism design“. Biol Lett 5:861-864

Gardner A, Grafen A. "Capturing the superorganism: a formal theory of group adaptation“. Journal of Evolutionary Biology. 2009;22:659-671.

Gardner A, West SA, Wild G. "The genetical theory of kin selection." Journal of Evolutionary Biology. 2011;24:1020-1043.

Gardner A. (2009) "Adaptation as organism design" Biology Letters. 2009;5:861864.

Gardner A. West S. (2010) “Greenbeards“. Evolution, 64:25-38.

Garson J (2017) “A Generalized Selected Effects Theory of Function”, Philosophy of Science, 84(3): 523-543. doi:10.1086/692146

Godfrey-Smith, P. (1994) A Modern History Theory of Functions, Noûs, 28 : 344-62.

Goodnight CJ, Schwartz JM, Stevens L.(1992) “ Contextual analysis of models of group selection, soft selection, hard selection, and the evolution of altruism." The American Naturalist. 140:743-761.

Goodnight CJ. (2002) "Multilevel selection: the evolution of cooperation in non kin groups". Population Ecology. 2005;47:3-12.

Grafen A. "Natural selection, kin selection and group selection". In: Krebs J, Davies N, eds. Behavioural Ecology: An Evolutionary Approach. Oxford: Blackwell; 1984:62-84.

Grafen, A. (2002) "A first formal link between the Price equation and an optimisation program.” J. Theor. Biol. 217: 75-91.

Grafen, A. (2006) "Optimisation of inclusive fitness." J. Theor. Biol. 238: 541-563.

Grafen, A. (2007) "The formal Darwinism project: a mid-term report." Journal of Evolutionary Biology, 20: 1243-1254.

Griffiths, P., 1993, "Functional Analysis and Proper Functions", The British Journal for the Philosophy of Science, 44(3): 409-422. doi:10.1093/bjps/44.3.409 
Griffiths, P, Stotz. K. 2013. Genetics and Philosophy: An Intro-duction. Cambridge:

Cambridge University Press.

Hall N. 2004, "Two Concepts of Causation" in J. Collins, N. Hall, and L. A. Paul (eds.), Causation and Counterfactuals, Cambridge, MA: The MIT Press, pp. 181-204. Hamilton W. (1963) "The genetic evolution of social behavior." Journal of Theoretical Biology. 1963;7:1-16.

Hempel, C. G. (1959) "The Logic of Functional Analysis“, in L. Gross (ed.), Symposium on Sociological Theory, New York: Harper and Row, pp. 271-87.

Hladký, V., Havlíček, J. (2013). "Was Tinbergen an Aristotelian? Comparison of Tinbergen's Four Whys and Aristotle's Four Causes“. Human Ethology Bulletin, 28(4): 3-11

Huneman P (2010) “Topological explanations and robustness in biological sciences." Synthese, 2010, 177: 213-245

Huneman P. (2012) "Natural selection: a case for the counterfactual approach", Erkenntnis, 76 (2): 171-194.

Huneman P. (2010) "Assessing the prospects for a return of organisms in evolutionary biology.", History and philosophy of life sciences, 32, 2/3: 341-372.

Huneman P. (2013b) "Assessing statistical views of natural selection: is there a room for non local causation?" Studies in History and Philosophy of Biological and Biomedical Sciences 44: 604-612

Huneman P. (2013a) "Weak realism in the etiological theory of functions", Functions: selection and mechanisms, Huneman (ed.), Dordrecht: Springer,, 13, pp.105-13.

Huneman P. (2014b) "A Pluralist Framework to Address Challenges to the Modern Synthesis in Evolutionary Theory”. Biological Theory, 9(2): 163-177.

Huneman P. (2014a) "Formal Darwinism and organisms in evolutionary biology: answering some challenges." Biology and Philosopby, 29 :271-279.

Huneman P. (2015) "Redesigning the argument from design." Paradigmi. 33, 2: 105-132.

Huneman P. (2015b) "Inscrutability and the opacity of selection and drift: distinguishing epistemic and metaphysical aspects", Erkenntnis, 80:491-518

Huneman P. (2018c) "Diversifying the picture of explanations in biological sciences: ways of combining topology with mechanisms" Synthese, 195 (1):115-146 Huneman P. (2019a) "The Multifaceted Legacy of the Human Genome Program for Evolutionary Biology: An Epistemological Perspective " Perspectives on Science, 27:1, 117-152

Huneman P. (2019b) "Revisiting darwinian teleology: A case for inclusive fitness as design explanation" Studies in History and Philosophy of Science Part C. doi.org/10.1016/j.shpsc.2019.101188.

Huneman, P. (2006) 'From Comparative Anatomy to the 'Adventures of Reason.'

"Studies in History and Philosophy of Biological and Biomedical Sciences, 37, 4: 649674.

Huxley J. (1942) Evolution: The Modern Synthesis. New York: Harper. Jablonka E., Lamb M. (2005) Evolution in four dimensions. Cambridge : MIT Press 
Jablonka, E., Raz G. (2009)"Transgenerational epigenetic inheritance: prevalence, mechanisms, and implications for the study of heredity and evolution." Quarterly Review of Biology 84: 131-176.

K.R Foster, T. Wenseleers, F.L.W. Ratnieks (2006) Kin selection is the key to altruism. Trends in Ecology and Evolution 21: 57-60.

Kant, I. [1790] (1987) Critique of Judgment. Trans. Werner S. Pluhar. Indianapolis: Hackett. (often translation revised) (noted CJ)

Kauffman, S. (1993) The Origins of Order: Self-Organization and Selection in Evolution.

New York: Oxford University Press.

Kelly, R. (1985) The Nuer Conquest. The Structure and Development of an Expansionist

System. Ann Arbor, The University of Michigan Press,

Kerr B, Godfrey-Smith P. "Individualist and multi-level perspectives on selection in structured populations“. Biology and Philosophy. 2002;17:477-517.

Kirscher, M., Gerhart J. (2005). The Plausibility of Life: Resolving Darwin's Dilemma. New Haven: Yale University Press.

Kitcher, P, 1993, "Function and Design", Midwest Studies in Philosophy, 18(1): 379_ 397.

Laland, K, Tobias U, Feldman M, Sterelny K, Müller GB, Moczek, John

Odling-Smee. 2014. "Does Evolutionary Theory Need a Rethink? Yes, Urgently."

Nature 514: 161-164.

Lehmann L, Keller L, West S, Roze D. (2007) "Group selection and kin selection: two concepts but one process." Proceedings of the National Academy of Sciences USA. 104:6736-6739.

Lewontin RC. (1970) "The units of selection." Annual Review of Ecology and Systematics. 1:1-18.

Lynch, M. (2005) The Origins of Genome Architecture. Sinauer Assocs., Inc., Sunderland, MA

Mayr, E. (1961) "Cause and Effect in Biology“. Science 134: 1501-1506.

McLaughlin, P. (2001)What Functions Explain. Functional Explanation and SelfReproducing Systems, Cambridge: Cambridge University Press.

Menzies P. 2004, "Difference-Making in Context," in J. Collins, N. Hall, and L. A. Paul (eds.), Causation and Counterfactuals, Cambridge, MA: The MIT Press, pp. 139_ 80.

Millikan, R. G. (1984) Language, Thought, and Other Biological Categories, Cambridge, MA: MIT Press.

Mossio, M., Saborido, C. and Moreno, A. (2009) "An Organizational Account of Biological Functions", British Journal for the Philosophy of Science, 60, pp. 813-41.

Müller G, Pigliucci M (2011) Evolution: the extended synthesis. MIT Press, Cambridge Müller, G B (2017) "Why an Extended Evolutionary Synthesis Is Necessary." Interface Focus 7: 20170015.

Nagel, E. (1961) The Structure of Science, London: Routledge \& Kegan Paul.

Neander, K. (1991) "Function as Selected Effects: The Conceptual Analyst's Defense“, Philosophy of Science, 58 : 168-84.

Neander K (1995) "Pruning the Tree of Life“. Br J Philos Sci 46:59-80

Odling-Smee J., Laland K., Feldman M. (2003) Niche construction. The neglected process in evolution. Princeton: Princeton University Press. 
Okasha S. (2006) The Levels of Selection in Evolution. Oxford: Oxford University Press.

Okasha S. (2018) Goals and agents in evolution. Oxford: Oxford University Press.

Oyama S, Griffiths P., Gray, R. (eds) (2001) Cycles of Contingency. Developmental Systems and Evolution, Cambridge, MIT Press.

Pigliucci, M. (2007) "Do we need an extended evolutionary synthesis ?" Evolution 61(12): 2743-9

Pigliucci, M., Müller, G. (eds.) (2011) Evolution: The Extended Synthesis Cambridge: MIT Press.

Raff R. (1996) The shape of life: genes, development, and the evolution of animal form, Chicago: University of Chicago Press.

Sober E, Wilson DS. (1998) Unto others. New Haven: Harvard University Press

Sober E. (1984) The Nature of Selection. Cambridge, MA: The MIT Press.

Taylor P, Wild S, Gardner A. (2007) "Direct fitness or inclusive fitness: how shall we model kin selection?" Journal of Evolutionary Biology. 20:301-309.

Taylor PD, Frank SA. "How to make a kin selection model". Journal of Theoretical Biology. 1996;180:27-37.

Tinbergen, N. (1963) "On Aims and Methods of Ethology," Zeitschrift für

Tierpsychologie, 20: 410-433.

Traulsen A, Nowak MA. (2006) "Evolution of cooperation by multilevel selection". Proceedings of the National Academy of Sciences USA. 103:10952-10955.

Uller, Tobias, Armin P. Moczek, Richard A. Watson, Paul M. Brakefield and Kevin N. Laland (2018) "Developmental Bias and Evolution: A Regulatory Network Perspective“ Genetics, 209, 4: 949-966

Wade M. (1977) "An experimental study of group selection". Evolution, 131:134153.

Walsh D (2003) "Fit and diversity: explaining adaptive evolution". Philos Si

70:280-301

Walsh D (2007) "The pomp of superfluous causes: the interpretation of evolutionary theory“. Philos Sci 74:281-303

Walsh D (2010) “Two neo-Darwinisms“. Hist Philos Life Sci 32(2-3):317-339

Walsh D. (2002) "Brentano's chestnuts." in Ariew A, Cummins R, Perlman M (eds.), Functions: New Essays in the Philosophy of Psychology and Biology. New-York: Oxford University Press, pp. 314.

Walsh D (1998) "The scope of selection: Sober and Neander on what natural selection explains“, Australasian Journal of Philosophy, 76:2, 250-264,

Walsh, D, Lewens T, Ariew A (2002) "Trials of Life: Natural Selection and Random Drift." Philosophy of Science 69: 452-473.

Walsh D, Ariew A, Mattehn M (2017) "Four Pillars of Statisticalism" Philosophy,

Theory and Practice in biology, 9, 1. doi.org/10.3998/ptb.6959004.0009.001

West-Eberhard, M.J. (2003), Developmental Plasticity and Evolution, Oxford: Oxford University Press.

West S, Wild J, Gardner A (2010) "The theory of genetic kin selection". J Evol Biol 24:1020-1043 
West SA, Griffin AS, Gardner A. (2007) " Social semantics: altruism, cooperation, mutualism, strong reciprocity and group selection“. Journal of Evolutionary Biology. 20:415-432.

Wilson DS, Dugatkin L. (1997) "Group selection and assortative interactions." The American Naturalist, 149:336-351.

Wilson DS. (2001) "Evolutionary biology: struggling to escape exclusively individual selection". Quarterly Review of Biology. 76: 199-206.

Wray, G. A., Hoekstra, H, Futuyma D, Lenski R, Mackay TFC, Schluter D,

Strassmann J. (2014) "Does Evolutionary Theory Need a Rethink? No, All Is

Well." Nature 514: 161-164.

Wright, L. (1973) "Functions" Philosophical Review, 82 : 139-68.

Acknowledgements. This paper stems from conversations and work with Andy Gardner, without whom nothing would have been possible. I am hugely grateful to him, and thank him for his reading of the first version of the text. I also thank Elena Pagni, as well as two anonymous reviewers for their reviews. I am thankful to Andrew McFarland for language checking. 